\title{
Development of a reliable and accurate algorithm to quantify the tumor immune stroma (QTiS) across tumor types
}

\author{
Rainer Christoph Miksch ${ }^{1, *}$, Jingcheng Hao ${ }^{1, *}$, Markus Bo Schoenberg ${ }^{1, *}$, Katharina \\ Dötzer $^{1}$, Friederike Schlüter ${ }^{1}$, Maximilian Weniger ${ }^{1}$, Shuai Yin ${ }^{1}$, Steffen Ormanns ${ }^{2}$, \\ Jan Goesta D'Haese ${ }^{1}$, Markus Otto Guba ${ }^{1}$, Jens Werner ${ }^{1,3}$, Barbara Mayer ${ }^{1}$ and \\ Alexandr V. Bazhin ${ }^{1,3}$ \\ ${ }^{1}$ Department of General, Visceral and Transplantation Surgery, Ludwig-Maximilians University, Munich, Germany \\ ${ }^{2}$ Department of Pathology, Ludwig-Maximilians University, Munich, Germany \\ ${ }^{3}$ German Cancer Consortium (DKTK), Partner Site Munich, Germany \\ *These authors contributed equally to this work
}

Correspondence to: Markus Bo Schoenberg, email: markus.schoenberg@med.uni-muenchen.de

Keywords: tumor-infiltrating lymphocytes; colorectal cancer; ovarian cancer; hepatocellular carcinoma; pancreatic cancer

Received: August 08, $2017 \quad$ Accepted: November 05, $2017 \quad$ Published: December 04, 2017

Copyright: Miksch et al. This is an open-access article distributed under the terms of the Creative Commons Attribution License 3.0 (CC BY 3.0), which permits unrestricted use, distribution, and reproduction in any medium, provided the original author and source are credited.

\section{ABSTRACT}

The tumor microenvironment plays an important role in the tumor biology. Overall survival of tumor patients after resection is influenced by tumor-infiltrating lymphocytes (TILs) as a component of the tumor stroma. However, it is not clear how to assess TILs in the tumor stroma due to heterogeneous methods in different cancer types. Therefore, we present a novel Quantification of the Tumor immune Stroma (QTiS) Algorithm to reliably and accurately quantify cells in the tumor stroma. Immunohistochemical staining of CD3 and CD8 cells in sections of metastatic colorectal cancer (mCRC), ovarian cancer (OvCa), hepatocellular carcinoma (HCC), and pancreatic ductal adenocarcinoma (PDAC), alltogether $\boldsymbol{N}=80$, was performed. Hot spots of infiltrating immune cells are reported in the literature. Reliability of the hot spot identification of TILs was examined by two blinded observers. Accuracy was tested in 1 and 3 hot spots using computed counting methods (ZEN 2 software counting (ZC), ImageJ software with subjective threshold (ISC) and ImageJ with color deconvolution (IAC)) and compared to manual counting. All tumor types investigated showed an accumulation of TILs in the tumor stroma (peri- and intratumoral). Reliability between observers indicated a high level consistency. Accuracy for CD8+/ CD3+ ratio and absolute cell count required 1 and 3 hot spots, respectively. ISC was found to be the best for paraffin sections, whereas IAC was ideal for frozen sections. ImageJ software is cost-effective and yielded the best results. In conclusion, an algorithm for quantification of tumoral stroma could be established. With this QTiS Algorithm counting of tumor stromal cells is reliable, accurate, and cost-effective.

\section{INTRODUCTION}

In recent years the understanding of tumors regarding their dynamic proliferation, growth and so their composition has changed. It has become increasingly clear that malignant neoplasms are also influenced by particular cellular and non-cellular tumor components, so called tumor stroma. The tumor stroma influences carcinogenesis and tumor biology [1]. This is in part why a mere description of tumor burden, such as in the TNM tumor staging system, does not always have a high predictive and prognostic value $[2,3]$. Therefore, immune cell infiltration, the most common examined tumor stromal cells have become a focus of intense research $[4,5]$. In several tumor types it has been reported that stromal cells such as fibroblasts may also have a regulatory function in the biologic behavior of malignancies [6]. 
The immune components of the tumor stroma especially $\mathrm{CD}^{+}$and $\mathrm{CD}^{+}$infiltrating cells have been reported frequently in different tumor types $[7,8]$. In fact, some studies suggest that peri- and intratumoral immune cell infiltration exceeds the established staging systems (i.e. TNM) in predictability [9]. Therefore, quantification of cancer infiltrating immune cells has been described as a new clinical score across different tumor types [1, 3, $10,11]$. Although many publications describe influence on survival, the methodological aspects such as sample preparation, description of sectioning, details of antibody staining, and counting methods have been often vague or not mentioned $[9,12,13]$. Contrary to that, there are quantification methods in immunohistochemistry (IHC) which are widely standardized. The Ki67 index for example is essential for neuroendocrine tumors in clinical practice. However, since its establishment different counting concepts were adopted. Because of these differences methodological studies were needed to identify the best counting methods [12-14]. Similarly, to provide predictive scoring of the tumor stroma across tumor types, the methods need to be well defined, reproducible and readily available. In this way results reported in the literature can be put into perspective and compared directly.

Based on this study a reliable and accurate algorithm to quantify the immune components of the tumor immune stroma across different tumor types (Hepatocellular carcinoma (HCC), pancreatic cancer (PDAC), ovarian cancer (OvCa), and metastatic colorectal cancer (mCRC)) is proposed.

\section{RESULTS}

\section{Immunohistochemistry}

Immunohistochemical analysis revealed a positive CD3 and CD8 staining in all cancer tissue sections of mCRC, OvCa, HCC, and PDAC (Figure 1). The cells were counted manually using 3 hot spots per slide and analyzed using descriptive statistics (Table 1). The highest level of $\mathrm{CD}^{+}$cell infiltration was found in mCRC samples, in PDAC and OvCa this level was intermediate and HCC samples showed the lowest level of the infiltration (Figure 2A). These differences were significant. No difference was found in the amount of the $\mathrm{CD}^{+}$cell infiltration in the tumor samples tested (Figure 2B). As expected amount of $\mathrm{CD}^{+}$cells were higher compared to $\mathrm{CD}^{+}$ones in $\mathrm{mCRC}$, OvCa, and PDAC (Figure 2).

\section{Reliability analysis}

Quantification results from 2 blinded observers for reliable detection of hot spots were compared using intraclass-correlation: 0.949 in mCRC, 0.843 in OvCa, 0.805 in HCC and 0.957 in PDAC. There was no significant difference in finding the largest hot spot in all tumor types comparing the 2 blinded observers (data not shown). Therefore, 1 observer showed high level of internal consistency.

\section{Accuracy analysis}

The $\mathrm{CD}^{+} / \mathrm{CD}^{+}$ratio in 1 hot spot compared to the mean of 3 hot spots was consistent in all groups: ICC was 0.902 in $\mathrm{mCRC}, 0.908$ in $\mathrm{OvCa}, 0.924$ in $\mathrm{HCC}$, and 0.885 in PDAC. The absolute cell count in 1 hot spot compared to the average in 3 hot spots did differ concerning regression coefficient $\mathrm{B}$ values over 1.2 for $\mathrm{mCRC}$, OvCa, and PDAC (ICC scores: 0.973 in mCRC, 0.945 in $\mathrm{OvCa}, 0.963$ in HCC, and 0.952 in PDAC). Comparison of the computed methods to the gold standard of manual counting showed mostly excellent accuracy (Figure 3 and Table 2). However, ZC in PDAC yielded inconsistencies with $\mathrm{ICC}=0.601$ and regression coefficient $\mathrm{B}=1.280$. ISC reached excellent results $(>0.900)$ in all groups (Table 2). IAC reached excellent accuracy in frozen sections of $\mathrm{mCRC}, \mathrm{OvCa}$, and $\mathrm{HCC}$ but not in PDAC (Table 2).

\section{Counting time and costs}

Furthermore, the counting time was compared for each tumor type and software (Table 3 ). Manual counting and Image J software with subjective threshold took most of the time, whereas time could be saved using computer assisted automatic counting methods (ZC and IAC). The presence of a microscope is required and presumed for each laboratory. The price for the hardware to connect the microscope and the computer was 2280.91€ (AxioVision, Carl Zeiss Inc., Germany). Whereas ImageJ can be downloaded for free, the ZEN 2 blue software costs $4152.64 €$. This amounts to $6433.55 €$ for the proprietary software-solution.

\section{DISCUSSION}

Evaluation of tumor tissue is mostly based on clinicopathologic staging systems. Nevertheless, tumor burden and further components of the tumormicroenvironment help to precise subtypes in different tumor types [9].

The tumor stroma which constitutes its microenvironment plays an important role in the understanding of tumor biology, progression, therapy, and lastly prognosis [1]. Especially, the immune system and its effector cells are known to influence prognosis [10]. For example higher numbers of $\mathrm{CD}^{+}$and $\mathrm{CD}^{+}$ TILs have been shown to favorably influence prognosis of various tumor types [5, 7, 9, 15-21]. Different authors described classifications of infiltrating immune cells in breast cancer [22], lung cancer [23], and colorectal cancer 
Table 1: Descriptive statistics of IHC analysis of tumor samples

\begin{tabular}{llcccc}
\hline Cell amount & mCRC & OvCa & HCC & PDAC \\
\hline CD3 & Minimum & 302 & 59 & 0 & 88 \\
& 25\% Percentile & 354.3 & 118 & 8.5 & 112.3 \\
& Median & 453 & 169.5 & 59.5 & 189 \\
& $75 \%$ Percentile & 524.3 & 216.5 & 98.75 & 279 \\
CD8 & Minimum & 23 & 5 & 0 & 0 \\
& 25\% Percentile & 90.75 & 38.5 & 2.75 & 77 \\
& Median & 127 & 87 & 64 & 115.5 \\
& 75\% Percentile & 146 & 119.8 & 116.3 & 152.8 \\
\hline
\end{tabular}

[9]. Furthermore, they suggested that these classifications could amend the classical TNM system [9, 11, 22, 23].

In order for scoring systems to be clinically useful, standardization is key. However, in the literature counting methods and definitions are not clear and therefore results differ [9, 23, 24]. It complicates comparison of studies [9, 15]. For other quantification methods standards do exist and help guide clinicians during daily routine [12-14, 25-27].

The aim of this study was to find the most reliable, accurate and affordable quantification of tumor immune stroma (QTiS) for routine clinical practice (Figure 4). In this study, the immune cell infiltration with $\mathrm{CD}^{+}$and $\mathrm{CD} 8^{+}$ cells was used as the most widely examined representative of the tumor immune stroma $[5,7,15-17,28]$. For other stromal cells, no such algorithm exists [29, 30].

The area with the highest density of $\mathrm{CD}^{+}$or $\mathrm{CD} 8^{+}$ T-lymphocytes was defined as hot spot [31, 32]. Manual counting was regarded as the gold standard which was compared to computated software results. Actually, this underlying assumption is supported by the literature [12, 13]. Hot spot selection under the microscope was shown to be quicker at a lower cost than whole slide image scanning as reported in the literature [33, 34]. Furthermore, high demands of data processing and storage are needed when the whole slide is scanned [33, 35]. A typical scanned slide requires approx. 4.6 GB of memory [34], whereas a picture of 1 hot spot requires between 2.4 and $3 \mathrm{MB}$.

According to the subjective selection of hot spots, 1 observer is justified and reliable. This is also used in clinical practice - e.g. counting of Ki67 [12, 13]. If a ratio is to be determined - e.g. $\mathrm{CD}^{+} / \mathrm{CD}^{+}$, quantification of 1 hot spot compared to the mean of ratios of 3 hot spots was equitable. Ratios are often used to describe cell groups and subgroups [36]. It gives a quick impression of the consisting cells.

If the absolute cell count is to be determined, quantification of the mean of 3 hot spots is recommended and reliable. To give an absolute cell count over an area many researchers do not reveal their methods. It is not clear, if the counted area is representative for the tumor section $[6,9,22,23]$. When using tissue microarray (TMA) at least the cores are punched out of the blocks [37] reflecting a smaller part of the tumoral tissue than in whole slides.
The QTiS Algorithm (Figure 4) recommends counting of at least 3 hot spots per section. Others used up to 5 areas [39]. Actually, research about TILs is mostly focused on cell quantification in the tumor stroma with defined high/low infiltration groups and subgroups [5, 8, 9, 22, 28].

Currently, computed counting methods are able to achieve acceptable accuracy when compared to manual counting as gold standard $[8,12,13]$. ZEN and Image J software are by far not the only possible methods $[6,8$, $9,22-24,31,37]$. As shown in our results background staining should be considered when selecting a method: ISC is accurate for sections with high background staining because it allows for human adjustments. IAC can be used in sections with low background staining. Furthermore, overlapping of cell layers may be a confounding factor. Therefore, subjective methods like ISC and IAC have an advantage over fully automated ZEN 2 software in helping differentiate cell clusters from single cells. Furthermore, ImageJ software is free and shows better results concerning cost and time - regarding training and experience - efficiency compared to ZEN 2 software and manual counting. Software used by other authors may differ and are dependent on access and funding [39].

This study has limitations: The algorithm to quantify the tumor immune stroma was performed with hot spots of $\mathrm{CD}^{+}$and $\mathrm{CD}^{+}$cells. On the one hand, these cell types present a small number of effector cells in the tumor stroma. On the other hand, $\mathrm{CD}^{+}$and $\mathrm{CD} 8^{+}$T-lymphocytes infiltrating tumor stroma are the most frequently published among different tumor types $[5,7,15-18,31,37,38,40]$. In this study 4 different counting methods were compared to each other statistically using ZEN and ImageJ software. There are far more counting methods described in the literature. Nevertheless, in this study examples of free and subjective software were compared to expensive and a fully automated counting software representatively. Lastly, this algorithm was developed in a limited set of samples. However, we used 80 different samples $n=10$ for any marker and tumor type. With this sample size the QTiS Algorithm was statistically consistent. Furthermore, the results showed comprehensible and reproducible differences depending on the selected sections and high background staining in paraffin (HCC, PDAC) or frozen sections (mCRC, OvCa)). 
Table 2: Different methods of the staining analysis compared to manual counting

\begin{tabular}{lccccc}
\hline Methods & & mCRC & OvCa & HCC & PDAC \\
\hline ZEISS - ZEN 2 blue: automated counting & ICC & 0.926 & 0.987 & 0.869 & 0.601 \\
& $\mathrm{~B}$ & 0.868 & 0.968 & 0.621 & 1.28 \\
ImageJ: subjective threshold & ICC & 0.973 & 0.992 & 0.955 & 0.934 \\
& $\mathrm{~B}$ & 0.851 & 1.03 & 0.723 & 0.914 \\
ImageJ: color deconvolution & ICC & 0.986 & 0.99 & 0.976 & 0.932 \\
& $\mathrm{~B}$ & 0.945 & 1.06 & 0.791 & 1.327 \\
\hline
\end{tabular}

Table 3: Counting time in minutes for each software

\begin{tabular}{lcccccccc}
\hline & \multicolumn{2}{c}{ Manual counting } & \multicolumn{2}{c}{ ZEISS - ZEN 2 blue } & \multicolumn{2}{c}{ ImageJ: subjective threshold } & \multicolumn{2}{c}{ ImageJ: color deconvolution } \\
\hline & Median & Range & Median & Range & Median & Range & Median & Range \\
\hline mCRC & $10 \mathrm{~min}$ & $1-12 \mathrm{~min}$ & $1 \mathrm{~min}$ & $1-2 \mathrm{~min}$ & $10 \mathrm{~min}$ & $5-14 \mathrm{~min}$ & $6 \mathrm{~min}$ & $4-7 \mathrm{~min}$ \\
OvCa & $10 \mathrm{~min}$ & $1-12 \mathrm{~min}$ & $1 \mathrm{~min}$ & $1-2 \mathrm{~min}$ & $10 \mathrm{~min}$ & $5-14 \mathrm{~min}$ & $6 \mathrm{~min}$ & $4-7 \mathrm{~min}$ \\
HCC & $10 \mathrm{~min}$ & $1-12 \mathrm{~min}$ & $2 \mathrm{~min}$ & $1-3 \mathrm{~min}$ & $5 \mathrm{~min}$ & $1-8 \mathrm{~min}$ & $10 \mathrm{~min}$ & $1-14 \mathrm{~min}$ \\
PDAC & $8 \mathrm{~min}$ & $1-12 \mathrm{~min}$ & $1 \mathrm{~min}$ & $1-2 \mathrm{~min}$ & $4 \mathrm{~min}$ & $1-9 \mathrm{~min}$ & $2 \mathrm{~min}$ & $1-3 \mathrm{~min}$ \\
\hline
\end{tabular}

With the newly developed QTiS Algorithm quantification of tumor immune stroma cells is reliable, accurate and cost effective.

\section{MATERIALS AND METHODS}

\section{Materials}

This study was approved and registered by the Human Tissue and Cell Research (HTCR) foundation (HCC: 2015-12, PDAC: 2016-04) and the Ethics Committee of the University of Munich (HCC: 395-16, PDAC: 807-16, OvCa: 278-04, mCRC: 252-04). For IHC staining of CD3 and CD8 frozen sections of $\mathrm{mCRC}$ and $\mathrm{OvCa}$ as well as paraffin sections of HCC and PDAC was used. Section preparation and selection were dependent on the current use of these tumor types in the laboratory: tissue of $\mathrm{mCRC}$ and $\mathrm{OvCa}$ has been available as frozen sections in our own laboratory, whereas tissue of $\mathrm{HCC}$ and PDAC has only been prepared as paraffin sections by the pathology department and HTCR. Staining was performed according to the type of section preparation. Altogether 80 sections of the 4 different tumor types were assessed. In each tumor type 20 slides were stained: 10 slides for CD3 and CD8 antigens each.

\section{Methods}

\section{Immunohistochemistry on frozen sections}

Immunohistochemistry on frozen sections was described previously [41-43]. Briefly, after surgical removal, tumor samples were snap frozen in liquid nitrogen. Serial sections $(5 \mu \mathrm{m})$ were prepared and fixed in acetone. Blocking of $\mathrm{Fc}$ receptors with $10 \% \mathrm{AB}$ serum and endogenous biotin using the avidin-biotin blocking kit was performed. Primary antibodies against CD3 (clone UCHT1, mouse IgG1, working concentration: $1.25 \mu \mathrm{g} / \mathrm{ml}$, source: Becton-Dickenson, NJ, US) and CD8 (clone $\mathrm{C} 8 / 144 \mathrm{~B}$, mouse $\mathrm{IgG1}$, working concentration: $3.0 \mu \mathrm{g} / \mathrm{ml}$, source: Dako, Hamburg, Germany) were incubated for $60 \mathrm{~min}$ at room temperature. MOPC-21 (mouse IgG1, working concentration: $3 \mu \mathrm{g} / \mathrm{ml}$, source: Sigma-Aldrich, Steinheim, Germany) was used as an isotype control. For detection, the Avidin-Biotincomplex staining method using a biotinylated antibody (rabbit anti mouse, polyclonal, dilution:1:2000, source: Dianova, Hamburg, Germany) and the horse-radish peroxidase labeled streptavidin (dilution:1:1000, source: Dianova) was performed according to the instruction of the manufacturer. 3-Amino-9-Ethylcarbozole was used as chromophore.

\section{Immunohistochemistry on paraffin sections}

Serial sections of $4 \mu \mathrm{m}$ were used. Anti-CD3 antibody (ab5690, Abcam PLC, United Kingdom) and anti-CD8 antibody (ab4055, Abcam PLC, United Kingdom) were utilized briefly modified to IHC staining protocol after establishment with 1:50 antibody concentrations [44]. Antigen retrival for CD3 was performed with citrate buffer $(\mathrm{pH}=6)$ for 30 minutes. CD8 with EDTA buffer $(\mathrm{pH}=8)$ for 15 minutes was established. The temperature was $96^{\circ} \mathrm{C}$ for antigen retrival. Negative control was performed by replacing the antibody with $5 \%$ bovine serum albumin (BSA)/phosphate buffered saline (PBS). The antibody and negative control have been stored overnight in $4^{\circ} \mathrm{C}$. We used anti-rabbit antibody for CD3 and anti-mouse for CD8, both with 1:200. Staining 
CD3 ${ }^{+}$TILs
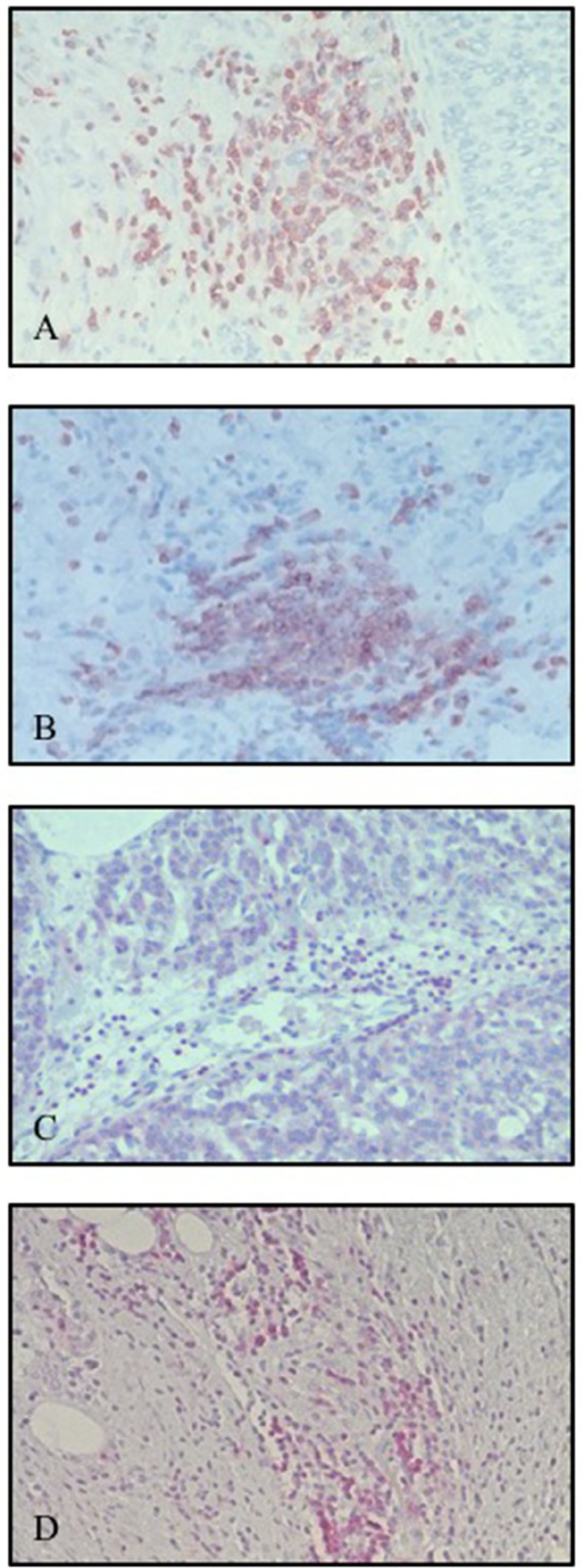

CD8 ${ }^{+}$TILs
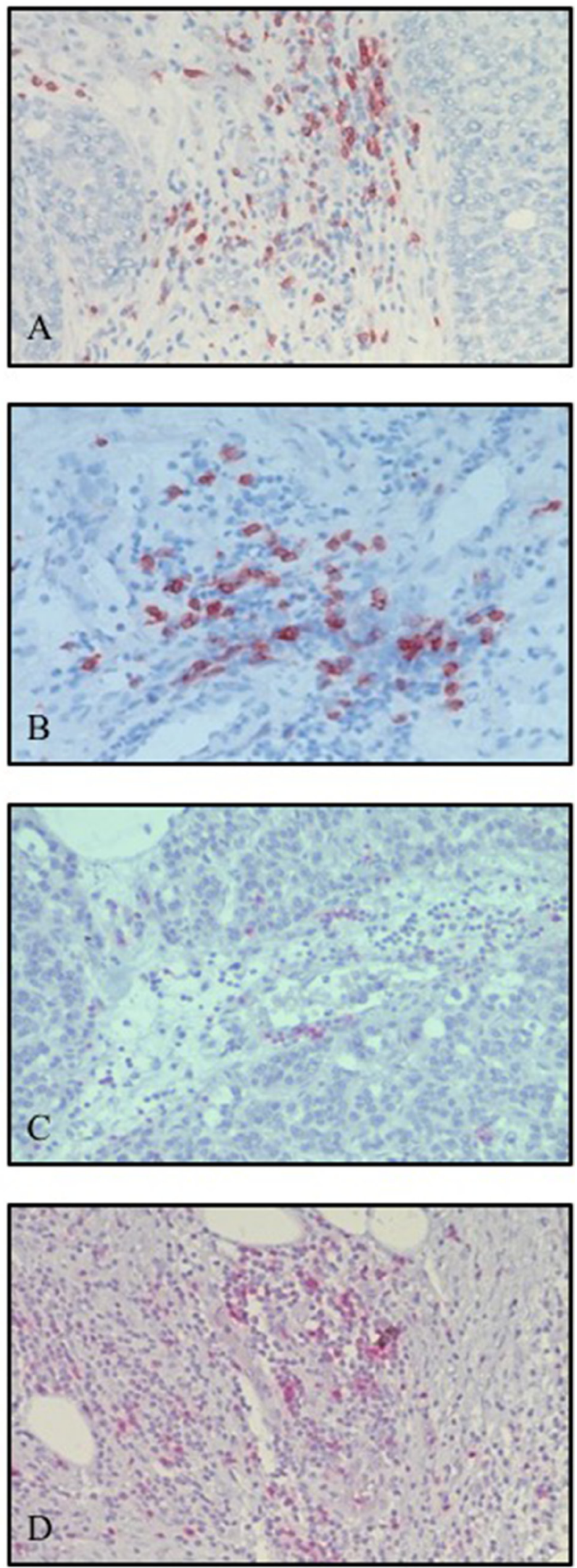

Figure 1: Representative hot spots of infiltrating $\mathrm{CD}^{+}$and $\mathrm{CD}^{+}$cells out of the same area using magnification of 20x (A) metastatic colorectal cancer, (B) ovarian cancer, (C) hepatocellular carcinoma, (D) pancreatic ductal adenocarcinoma). 
was performed with VECTASTAIN ABC-AP Staining KIT (AK-5000, Alkaline Phosphatase, Vector Laboratories Inc., USA) as described by manufacturer.

\section{IHC controls in HCC and PDAC}

Haemotoxylin was used as a counterstaining for both frozen and paraffin sections. Positive and

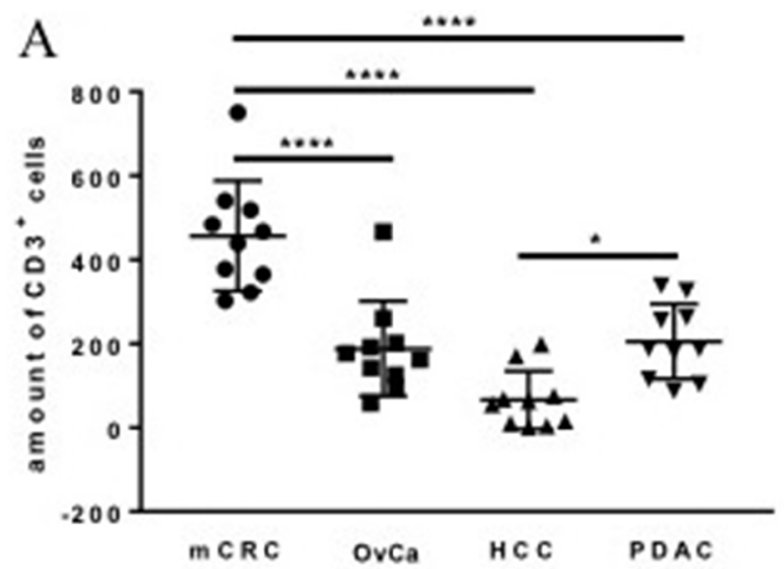

negative controls were performed as appropriate: tonsil tissue used as positive control. Quality control after immunohistochemistry was implemented according to Maxwell et al. [45]. The portion of cancer cells, the extent of necrosis, staining intensity, uniformity, specificity, absence of background staining, and counterstaining were quantified. Only optimal sections and stainings were permissible for this study [46].



Figure 2: Amount of $\mathrm{CD}^{+}(\mathbf{A})$ and $\mathrm{CD} 8^{+}$cells identified with $\mathrm{IHC}$ in tumor samples. The data of staining of 10 patients from each group are presented with SD and analyzed with the ordinary one-way ANOVA with Tukey's multiple comparisons post test, ${ }^{*} p<0.05$ and ${ }^{* * * *} p<$ 0.0001: significant difference in the amount of T cells is shown.
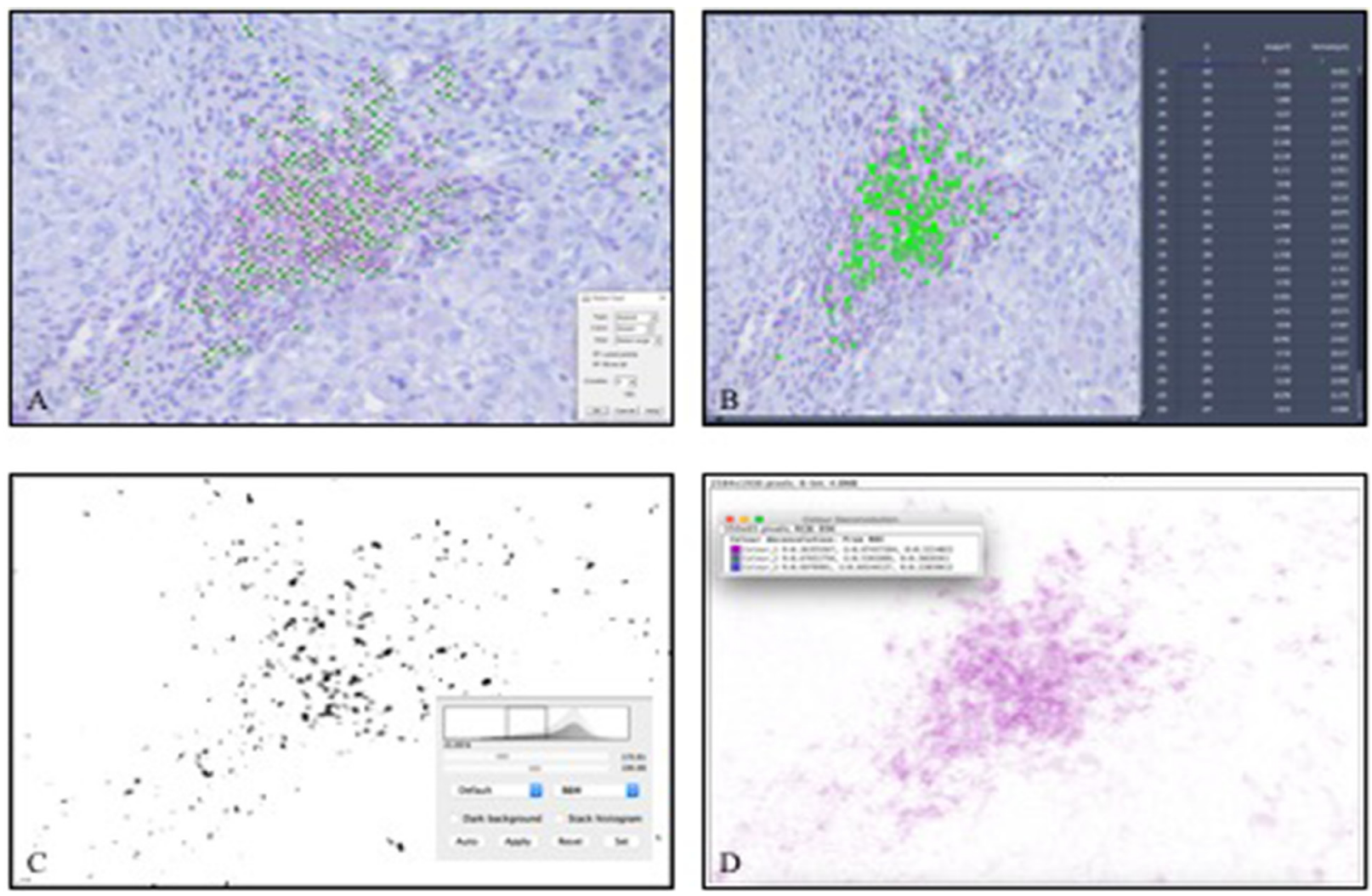

Figure 3: Manual counting and software-assisted counting methods shown representatively in one hot spot of infiltrating $\mathbf{C D 3}^{+}$T-lymphocytes in hepatocellular carcinoma. (A) manual counting with ImageJ software, (B) Automated ZEN 2 software counting, (C) ImageJ software with subjective threshold, (D) ImageJ software with color deconvolution). 


\section{Picture capturing and analysis}

The slides were visualized under the microscope (BX41, Olympus Corporation, Japan). Images of hot spots were captured with 200x enlargement using ZEN software (ZEN Version 2.0, Carl Zeiss Inc., Germany). 3 hot spots were evaluated in every slide. A hot spot was defined as the area with the highest density of infiltrating T-lymphocytes $[9,38]$, excluding lymph nodes. Included slides had at least one peri- or intratumoral hot spot. Biggest hot spots were selected by two blinded observers subjectively.

\section{Manual counting}

We defined manual counting as the gold standard [14]. Using the ImageJ Software, the infiltrating immune cells were manually counted by the functions "Analyze" and "Cell Counter".

\section{Algorithm}

Reliability and accuracy of computed quantification was tested in order to develop a general algorithm usable for all tumor types analyzed: First, the reliability of identification of hot spots was investigated using two blinded observers (RCM, JH for HCC and PDAC; KD, FS for $\mathrm{mCRC}$ and $\mathrm{OvCa}$ ). The absolute amounts of cells

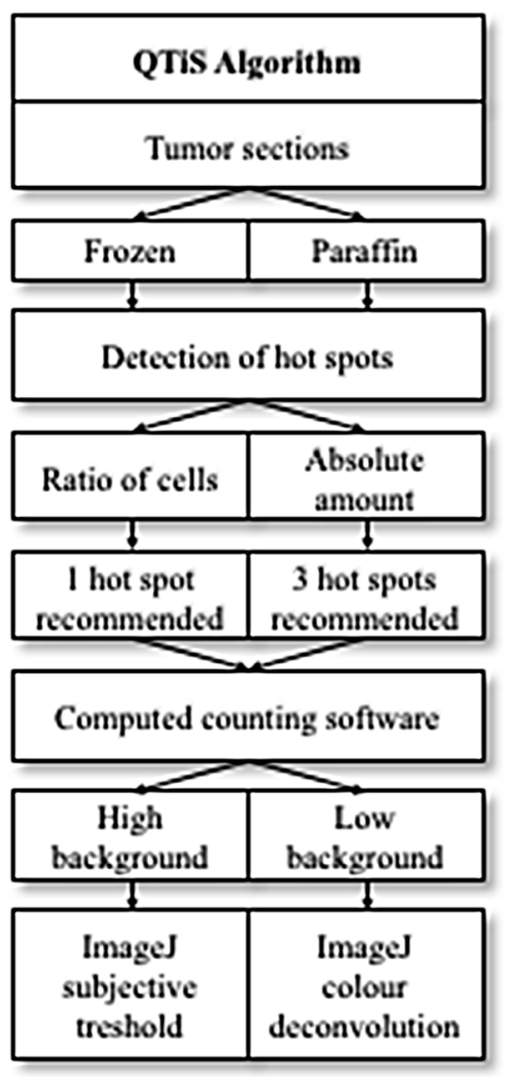

were compared with the intraclass correlation coefficient (ICC) to identify differences between two blinded observers.

Second, accuracy was tested. This experiment was divided in two parts. To examine whether quantification of 1 vs 3 hot spots yields accurate results the $\mathrm{CD} 8^{+} / \mathrm{CD}^{+}$ ratio as well as the absolute cell numbers were compared with the ICC respectively. Most authors described analysis of 3 hot spots [9, 15, 24]. Therefore, the most populated $\mathrm{CD}^{+}$hot spots of the slides were chosen, then the same hot spot was detected in the $\mathrm{CD} 8^{+}$slides and the ratio of $\mathrm{CD}^{+} / \mathrm{CD}^{+}$cells was calculated.

Third, the following computerized counting methods: ZEN 2 software counting (ZC), ImageJ software (U. S. National Institutes of Health, USA) with subjective threshold (ISC) and ImageJ with color deconvolution (IAC) were compared to a manual counting (gold standard) using a linear regression analysis. Furthermore, duration to count one hot spot and costs were compared for every method.

\section{Automated ZEN 2 software counting (ZC)}

The image analysis was configured by defining the measuring frame. Then, automatic segmentation by specification of the color spectrum was included. Finally, we defined the measurement features (scope, area, color

\section{What do I have?}

What do I want to count?

How should I count my cells?

Figure 4: Quantification of the Tumor immune Stroma (QTiS) Algorithm: From the type of tumor sections to the final quantification of the tumor immune stroma. 
spectrum, density, and watershed) and measured the stained cells. These steps were standardized for each antibody and each tumor type: the saved measurement features for CD3 and CD8 were used respectively.

\section{ImageJ with subjective threshold (ISC)}

First, the original picture was changed to a 32-bit format and the subjective staining threshold defined using the standard ImageJ software. With the so called watershed function a separation of larger particles was performed. These particles were then automatically counted using the software function "analyze particles" for quantification.

\section{ImageJ with color deconvolution (IAC)}

The color deconvolution application for ImageJ is freely available as an add on tool to the standard software [46]. The original picture of a hot spot was split in three color spectra. Furthermore, it was converted into a binary picture. Quantification of red particles is performed using watershed application of marked areas [47].

\section{Statistical analysis}

For statistical analysis SPSS statistics software (SPSS Version 24.0, IBM Corporation, USA) was used. In the descriptive statistics the amount of infiltrating cells was calculated as median and range in quartiles. For comparison on the continuous scale the Mann-Whitney $\mathrm{U}$ Test was employed when appropriate $\left(\mathrm{n}_{1}+\mathrm{n}_{2}>30\right)$. A $p$-value of 0.05 was considered statistically significant. Reliability and accuracy were tested by linear regression and reliability analysis to present values of ICC and regression coefficient $\mathrm{B}$.

\section{Abbreviations}

mCRC: metastatic colorectal cancer; HCC: hepatocellular carcinoma; IAC: ImageJ with color deconvolution; ICC: intraclass correlation coefficient; IHC: immunohistochemistry; ISC: ImageJ software with subjective treshold; OvCa: ovarian cancer; PDAC: pancreatic ductal adenocarcinoma; QTiS: Quantification of the Tumor immune stroma; TMA: tissue microarray; TIL: Tumor-infiltrating lymphocyte; ZC: ZEN 2 software counting.

\section{Author contributions}

R.C.M., J.H., and M.B.S. contributed equally to this work and R.C.M. and M.B.S. wrote the paper. R.C.M., J.H., M.B.S., B.M., and A.V.B. developed the concept and designed experiments.

R.C.M., J.H., K.D., F.S., and S.Y. performed experiments, analysed data; S.O. supervised the tissue preparation; M.W., J.G.D., M.O.G., and J.W. administered this work.

All authors discussed the results and implications and commented on the manuscript at all stages.

\section{ACKNOWLEDGMENTS}

The authors thank Alexander Crispin, MPH for his advices in statistical analysis and proper use of the methods. The authors thank Tobias Schiergens and HTCR for tissue samples. Additionally, the authors thank Doris Mayr for viability check of the OvCa slides. Furthermore, the authors appreciate Michaela Svihla, Anne Wagner, and Karin Enderle for support in immunohistochemistry. The authors thank Dana Dacian for administrative support.

\section{CONFLICTS OF INTEREST}

The authors declare no conflicts of interest.

\section{Editorial note}

This paper has been accepted based in part on peerreview conducted by another journal and the authors' response and revisions as well as expedited peer-review in Oncotarget.

\section{REFERENCES}

1. Fridman WH, Pages F, Sautes-Fridman C, Galon J. The immune contexture in human tumours: impact on clinical outcome. Nat Rev Cancer. 2012; 12:298-306.

2. Bindea G, Mlecnik B, Fridman WH, Pages F, Galon J. Natural immunity to cancer in humans. Curr Opin Immunol. 2010; 22:215-22.

3. Bindea G, Mlecnik B, Fridman WH, Galon J. The prognostic impact of anti-cancer immune response: a novel classification of cancer patients. Semin Immunopathol. 2011; 33:335-40.

4. Yang JJ, Hu ZG, Shi WX, Deng T, He SQ, Yuan SG. Prognostic significance of neutrophil to lymphocyte ratio in pancreatic cancer: a meta-analysis. World J Gastroenterol. 2015; 21:2807-15.

5. Gabrielson A, Wu Y, Wang H, Jiang J, Kallakury B, Gatalica Z, Reddy S, Kleiner D, Fishbein T, Johnson L, Island E, Satoskar R, Banovac F, et al. Intratumoral CD3 and CD8 T-cell Densities Associated with Relapse-Free Survival in HCC. Cancer Immunol Res. 2016; 4:419-30.

6. De Monte L, Reni M, Tassi E, Clavenna D, Papa I, Recalde H, Braga M, Di Carlo V, Doglioni C, Protti MP. Intratumor $\mathrm{T}$ helper type 2 cell infiltrate correlates with cancer-associated fibroblast thymic stromal lymphopoietin production and reduced survival in pancreatic cancer. J Exp Med. 2011; 208:469-78. 
7. Sun C, Xu J, Song J, Liu C, Wang J, Weng C, Sun H, Wei H, Xiao W, Sun R, Tian Z. The predictive value of centre tumour $\mathrm{CD} 8(+) \mathrm{T}$ cells in patients with hepatocellular carcinoma: comparison with Immunoscore. Oncotarget. 2015; 6:35602-15. https://doi.org/10.18632/ oncotarget.5801

8. Karakhanova S, Ryschich E, Mosl B, Harig S, Jager D, Schmidt J, Hartwig W, Werner J, Bazhin AV. Prognostic and predictive value of immunological parameters for chemoradioimmunotherapy in patients with pancreatic adenocarcinoma. Br J Cancer. 2015; 112:1027-36.

9. Anitei MG, Zeitoun G, Mlecnik B, Marliot F, Haicheur N, Todosi AM, Kirilovsky A, Lagorce C, Bindea G, Ferariu D, Danciu M, Bruneval P, Scripcariu V, et al. Prognostic and predictive values of the immunoscore in patients with rectal cancer. Clin Cancer Res. 2014; 20:1891-9.

10. Mlecnik B, Bindea G, Kirilovsky A, Angell HK, Obenauf AC, Tosolini M, Church SE, Maby P, Vasaturo A, Angelova M, Fredriksen T, Mauger S, Waldner M, et al. The tumor microenvironment and Immunoscore are critical determinants of dissemination to distant metastasis. Sci Transl Med. 2016; 8:327ra26.

11. Galon J, Pages F, Marincola FM, Thurin M, Trinchieri G, Fox BA, Gajewski TF, Ascierto PA. The immune score as a new possible approach for the classification of cancer. $\mathrm{J}$ Transl Med. 2012; 10:1.

12. Reid MD, Bagci P, Ohike N, Saka B, Erbarut Seven I, Dursun N, Balci S, Gucer H, Jang KT, Tajiri T, Basturk O, Kong SY, Goodman M, et al. Calculation of the Ki67 index in pancreatic neuroendocrine tumors: a comparative analysis of four counting methodologies. Mod Pathol. 2016; 29:93.

13. Reid MD, Bagci P, Ohike N, Saka B, Erbarut Seven I, Dursun N, Balci S, Gucer H, Jang KT, Tajiri T, Basturk O, Kong SY, Goodman M, et al. Calculation of the Ki67 index in pancreatic neuroendocrine tumors: a comparative analysis of four counting methodologies. Mod Pathol. 2015; 28:686-94.

14. Kroneman TN, Voss JS, Lohse CM, Wu TT, Smyrk TC, Zhang L. Comparison of Three Ki-67 Index Quantification Methods and Clinical Significance in Pancreatic Neuroendocrine Tumors. Endocr Pathol. 2015; 26:255-62.

15. Kwak Y, Koh J, Kim DW, Kang SB, Kim WH, Lee HS. Immunoscore encompassing $\mathrm{CD} 3+$ and $\mathrm{CD} 8+\mathrm{T}$ cell densities in distant metastasis is a robust prognostic marker for advanced colorectal cancer. Oncotarget. 2016; 7:8177890. https://doi.org/10.18632/oncotarget.13207.

16. Fukunaga A, Miyamoto M, Cho Y, Murakami S, Kawarada Y, Oshikiri T, Kato K, Kurokawa T, Suzuoki M, Nakakubo Y, Hiraoka K, Itoh T, Morikawa T, et al. CD8+ tumorinfiltrating lymphocytes together with $\mathrm{CD} 4+$ tumorinfiltrating lymphocytes and dendritic cells improve the prognosis of patients with pancreatic adenocarcinoma. Pancreas. 2004; 28:e26-31.
17. Ene-Obong A, Clear AJ, Watt J, Wang J, Fatah R, Riches JC, Marshall JF, Chin-Aleong J, Chelala C, Gribben JG, Ramsay AG, Kocher HM. Activated pancreatic stellate cells sequester CD8 $+\mathrm{T}$ cells to reduce their infiltration of the juxtatumoral compartment of pancreatic ductal adenocarcinoma. Gastroenterology. 2013; 145:1121-32.

18. Ademmer K, Ebert M, Muller-Ostermeyer F, Friess H, Buchler MW, Schubert W, Malfertheiner P. Effector T lymphocyte subsets in human pancreatic cancer: detection of CD8+CD18+ cells and CD8+CD103+ cells by multiepitope imaging. Clin Exp Immunol. 1998; 112:21-6.

19. Santoiemma PP, Reyes C, Wang LP, McLane MW, Feldman MD, Tanyi JL, Powell DJ Jr. Systematic evaluation of multiple immune markers reveals prognostic factors in ovarian cancer. Gynecol Oncol. 2016; 143:120-7.

20. Okabe M, Toh U, Iwakuma N, Saku S, Akashi M, Kimitsuki Y, Seki N, Kawahara A, Ogo E, Itoh K, Akagi Y. Predictive factors of the tumor immunological microenvironment for long-term follow-up in early stage breast cancer. Cancer Sci. 2017; 108:81-90.

21. Rodriguez-Vida A, Strijbos M, Hutson T. Predictive and prognostic biomarkers of targeted agents and modern immunotherapy in renal cell carcinoma. ESMO Open. 2016; 1:e000013.

22. Curigliano G, Perez EA. Immunoscoring breast cancer: TILs remember what they target. Ann Oncol. 2014; 25:1455-6.

23. Donnem T, Kilvaer TK, Andersen S, Richardsen E, Paulsen EE, Hald SM, Al-Saad S, Brustugun OT, Helland A, Lund-Iversen M, Solberg S, Gronberg BH, Wahl SG, et al. Strategies for clinical implementation of TNMImmunoscore in resected nonsmall-cell lung cancer. Ann Oncol. 2016; 27:225-32.

24. Jiang Y, Zhang Q, Hu Y, Li T, Yu J, Zhao L, Ye G, Deng H, Mou T, Cai S, Zhou Z, Liu H, Chen G, et al. ImmunoScore Signature: A Prognostic and Predictive Tool in Gastric Cancer. Ann Surg. 2016 Dec 20. https://doi.org/10.1097/ SLA.0000000000002116. [Epub ahead of print].

25. Yorozuya K, Takeuchi T, Yoshida M, Mouri Y, Kousaka J, Fujii K, Nakano S, Fukutomi T, Hara K, Ichihara S, Lin Y, Kikuchi S. Evaluation of Oncotype DX Recurrence Score as a prognostic factor in Japanese women with estrogen receptor-positive, node-negative primary Stage I or IIA breast cancer. J Cancer Res Clin Oncol. 2010; 136:939-44.

26. Bartley $\mathrm{AN}$, Washington $\mathrm{MK}$, Ventura $\mathrm{CB}$, Ismaila $\mathrm{N}$, Colasacco C, Benson AB 3rd, Carrato A, Gulley ML, Jain D, Kakar S, Mackay HJ, Streutker C, Tang L, et al. HER2 Testing and Clinical Decision Making in Gastroesophageal Adenocarcinoma: Guideline From the College of American Pathologists, American Society for Clinical Pathology, and American Society of Clinical Oncology. Arch Pathol Lab Med. 2016; 140:1345-63.

27. Prendeville S, Corrigan MA, Livingstone V, Feeley L, Bennett MW, Browne TJ, O'Connell F. Optimal Scoring of 
Brightfield Dual-Color In Situ Hybridization for Evaluation of HER2 Amplification in Breast Carcinoma: How Many Cells Are Enough? Am J Clin Pathol. 2016; 145:316-22.

28. Li J, Wang J, Chen R, Bai Y, Lu X. The prognostic value of tumor-infiltrating $\mathrm{T}$ lymphocytes in ovarian cancer. Oncotarget. 2017; 8:15621-31. https://doi.org/10.18632/ oncotarget.14919.

29. Erdogan B, Webb DJ. Cancer-associated fibroblasts modulate growth factor signaling and extracellular matrix remodeling to regulate tumor metastasis. Biochem Soc Trans. 2017; 45:229-36.

30. Hu M, Qian C, Hu Z, Fei B, Zhou H. Biomarkers in Tumor Microenvironment? Upregulation of Fibroblast Activation Protein-alpha Correlates with Gastric Cancer Progression and Poor Prognosis. OMICS. 2017; 21:38-44.

31. Kmiecik J, Poli A, Brons NH, Waha A, Eide GE, Enger PO, Zimmer J, Chekenya M. Elevated CD3+ and CD8+ tumorinfiltrating immune cells correlate with prolonged survival in glioblastoma patients despite integrated immunosuppressive mechanisms in the tumor microenvironment and at the systemic level. J Neuroimmunol. 2013; 264:71-83.

32. Zidlik V, Brychtova S, Uvirova M, Ziak D, Dvorackova J. The changes of angiogenesis and immune cell infiltration in the intra- and peri-tumoral melanoma microenvironment. Int J Mol Sci. 2015; 16:7876-89.

33. Pantanowitz L, Valenstein PN, Evans AJ, Kaplan KJ, Pfeifer JD, Wilbur DC, Collins LC, Colgan TJ. Review of the current state of whole slide imaging in pathology. J Pathol Inform. 2011; 2:36.

34. Park S, Pantanowitz L, Parwani AV. Digital imaging in pathology. Clin Lab Med. 2012; 32:557-84.

35. Indu M, Rathy R, Binu MP. "Slide less pathology": Fairy tale or reality? J Oral Maxillofac Pathol. 2016; 20:284-8.

36. Hwang HK, Kim HI, Kim SH, Choi J, Kang CM, Kim KS, Lee WJ. Prognostic impact of the tumor-infiltrating regulatory T-cell (Foxp3+)/activated cytotoxic T lymphocyte (granzyme $\mathrm{B}+$ ) ratio on resected left-sided pancreatic cancer. Oncol Lett. 2016; 12:4477-84.

37. Kai K, Masuda M, Aishima S. Inverse correlation between CD8+ inflammatory cells and E-cadherin expression in gallbladder cancer: Tissue microarray and imaging analysis. World J Clin Case. 2017; 5:1-8.
38. Gooden MJ, de Bock GH, Leffers N, Daemen T, Nijman HW. The prognostic influence of tumour-infiltrating lymphocytes in cancer: a systematic review with metaanalysis. Br J Cancer. 2011; 105:93-103.

39. Schneider CA, Rasband WS, Eliceiri KW. NIH Image to ImageJ: 25 years of image analysis. Nat Methods. 2012; 9:671-5.

40. Munks MW, Mourich DV, Mittler RS, Weinberg AD, Hill AB. 4-1BB and OX40 stimulation enhance CD8 and CD4 T-cell responses to a DNA prime, poxvirus boost vaccine. Immunology. 2004; 112:559-66.

41. Mayer B, Johnson JP, Leitl F, Jauch KW, Heiss MM, Schildberg FW, Birchmeier W, Funke I. E-cadherin expression in primary and metastatic gastric cancer: downregulation correlates with cellular dedifferentiation and glandular disintegration. Cancer Res. 1993; 53:1690-5.

42. Mayer B, Lorenz C, Babic R, Jauch KW, Schildberg FW, Funke I, Johnson JP. Expression of leukocyte cell adhesion molecules on gastric carcinomas: possible involvement of LFA-3 expression in the development of distant metastases. Int J Cancer. 1995; 64:415-23.

43. Mayer B, Funke I, Johnson JP. High expression of a Lewis(x)-related epitope in gastric carcinomas indicates metastatic potential and poor prognosis. Gastroenterology. 1996; 111:1433-46.

44. abcam. IHC staining protocol for paraffin, frozen and free floating sections. In: 2017; http://www.abcam.com/ protocols/immunostaining-paraffin-frozen-free-floatingprotocol\#Paraffin\%20and\%20frozen.

45. Maxwell P, McCluggage WG. Audit and internal quality control in immunohistochemistry. J Clin Pathol. 2000; 53:929-32.

46. Ruifrok AC, Johnston DA. Quantification of histochemical staining by color deconvolution. Anal Quant Cytol Histol. 2001; 23:291-9.

47. Vayrynen JP, Vornanen JO, Sajanti S, Bohm JP, Tuomisto A, Makinen MJ. An improved image analysis method for cell counting lends credibility to the prognostic significance of $\mathrm{T}$ cells in colorectal cancer. Virchows Arch. 2012; 460:455-65. 